\title{
The Appropriate Educational Role for the Jordanian Secondary Schools based on Hoshin Kanri Methodology to develop their Quality Culture
}

\author{
Dr. Zakaria Almobasheir, The Applied Science Private University, Amman, Jordan, z_almobasheir@asu.edu.jo, \\ Ala' Hashem Hitriyeh, Mayar International Schools, Amman, Jordan, ahitiryeh@yahoo.com,
}

\begin{abstract}
The current study aimed to identify the appropriate educational role for Jordanian secondary schools to develop their quality culture based on Hoshin Kanri methodology. To achieve the purpose of the study, a qualitative design based on content analysis was used. The findings of the study revealed that the appropriate educational role included the activities, practices and plans on which secondary schools are based, in addition to the focus on implementing quality culture through the role of schools' principals, teachers and personnel, and employing it in the fields and aspects related to secondary schools.
\end{abstract}

Keywords: The Educational Role, Quality Culture, Hoshin Kanri, Secondary Schools, Jordan.

Received: 16.12.2020 $\quad$ Accepted: 22.01.2021 $\quad$ Published: 08.02.2021

\section{Introduction}

The educational system is one of the important social systems, as its main tasks include the contribution to the service and development of society. Therefore, the educational institutions have to enhance the role of the educational leaderships that work to meet the evolution and development demands of the modern era. In fact, the success of any institution depends on the effectiveness of the human element, as well as the extent to which $\mathrm{He}$ is able to complete the work. The educational process is a human-based one characterized by the effectiveness and its pursuit to fulfill humanitarian goals. The leadership of the educational system addresses various dimensions of the educational process using the human element. Accordingly, the educational leaders must have sufficient understanding and awareness of how a person could be guided, and how to deal with him in a way ensures that he takes advantage of his full potential, for completing his work or the role he plays, convinced by the importance of this effort in achieving the educational goals (Abdel-Daim, 2015).

Adopting the concepts of quality management is of a strategic importance in the educational systems, which is reflected positively on the educational institutions due to including the quest for continuous renewal, and the search for factors increasing their efficiency and creativity In line with the rapid and successive developments and changes witnessed by the era in all sectors. From time to time, the educational administration finds itself in front of challenges requiring it to dispense with the principles and methods it used formerly. Therefore, the implementation of modern principles and methods in the educational institutions is extremely critical (Sharon, 2017).

Although, there were many efforts to define the concept of quality in the educational system, its elements, and standards, the primary overall objective of applying quality system is still representing the outcome of the educational institutions' efforts in general. Whereas, the term quality in education has come to refer to the entire efforts made by the personnel (teachers and administrators) of the educational institution in order to increase the learning outcomes level in line with society's requirements (Gouili, 2017).

In this response, several strategies related to total quality has emerged, including Hoshin Kanri strategy, a strategy used in Japanese organizations with a view to managing quality and enabling managers to understand the higher-order goals by linking an institution's interim and strategic goals. Furthermore, it brings many benefits to the institutions, such as integrating strategic goals with daily planning management, applying the planning cycle to the management process, a parallel methodology for planning and implementation, improving communications, a growing consensus upon setting the objectives, and the integration of management functions. As for the elements included in the model, they are: a vision for the next five years, an annual plan, goals deployment, detailed implementation, and diagnosis (Witcher, 2014).

Although its use in institutions of Western countries is often limited to some large-scale institutions, Hoshin Kanri methodology is a common model in the Japanese institutions. The issue of implementing this 
methodology was not the focus of the studies and researches conducted in the field of Management Science, although it provides an effective tool in increasing the level of organizational operations at all levels, as the leader of an organization can make a radical change in the institutions' organizational culture, which is positively reflected in enhancing the quality of operations (Nicholas, 2014).

Hoshin Kanri's model provides an annual detailed plan, which includes both: planning and deployment processes. The implementation of this plan would characterize the strategic planning process by a level of flexibility, creativity and effectiveness. The personnel of the institutions contribute to translating its objectives into actions, as this makes them to have a sense of belonging to the institution and a sense that they have a role in improving the processes associated with providing institutional services which will be, therefore, reflected positively on the quality of their performance and productivity (Barton \& Ambrosini, 2013).

Furthermore, Hoshin Kanri's model has a key role in the administrative tasks related to the institution's daily activities, whereas each department of it is considered responsible for the outcomes of the activities associated with it. In the event that the model was fully applied in the institution, this indicates the institution's commitment to organize its daily operations and set a timeline for performance. In addition to that, Hoshin Kanri's model includes the implementation of accountability and responsibility of senior management about the decisions taken by them, the process of setting objectives, and communicating with personnel at various levels. Improvements on performance are made through the efforts to be made by the workers in the departments. During that, the weaknesses and gaps that may appear during the work are focused on, and ensuring a high level of quality within one department is maintained (Zairi \& Alan, 2014).

\section{Study Problem}

The problem of the study is based on the experience of the two researchers in the educational field, as well as their participation in many meetings and seminars concerning the quality of education in Jordan. According to the international tests in a number of school subjects, such as "Timss" and "Pisa", a decrease in the education outcomes compared to the schools' global ranking has been observed. Hence, a review of schools' education structure are required for being able to provide a clear and distinct message and vision about education in line with quality culture, which works on developing the educational institutions and society as well.

The current study problem is to answer the following question: What is the appropriate educational role for Jordanian secondary schools based on Hoshin Kanri methodology to develop their quality culture?

\section{Study Objectives}

The study aimed to identify the appropriate educational role for Jordanian secondary schools based on Hoshin Kanri methodology to develop their quality culture.

\section{Study Significance}

The importance of the current study can be illustrated as follows:

- Theoretical Significance: The Significance of the study stems from the importance of the information reached by referring to the previous literature. To the researchers' limited knowledge, this study is among the pioneering studies that came to discuss a proposed educational role for secondary schools based on Hoshin Kanri methodology to develop their quality culture, as it topic has not been discussed previously. Therefore, It constitutes a new addition to the Arab Library.

- Practical Significance: Hopefully, the Ministry of Education will benefit from the findings of the study in order to develop quality culture, train school personnel on it and link professional development to quality culture and its principles implementation level by finding appropriate standards for its evaluation.

\section{Study Key Terms \\ - Role}

Theoretical definition: a pattern of actions by an individual, group or institution in the various social situations, and accepted by the group in light of the behavior standards prevalent in a culture (Nasser, 2011).

Operational definition: It is the tasks and actions performed by school personnel in line with the school's vision, philosophy, educational activities, communication and connection with the local community using its educational strategies.

- Quality Culture

Theoretical definition: It is the institutional culture that aims to raise and improve the quality of the educational process. It includes two important components, namely: the cultural and psychological components related to 
values and beliefs, commitment, expectations about education and its results, and the structural and administrative components related to the improvement of procedures, practices and making efforts towards achieving the goals of quality implementation in the institutional system (Sattler \& Sonntag, 2019).

Operational definition: It is the adherence to clear standards in order to reach the service's highest levels of quality, and then deploy them in the culture of the institution.

- Hoshin Kanri

Theoretical definition: It is a set of strategic management practices adopted by the leading Japanese companies in order to raise the level and quality of provided services (Alic \& Ideskog, 2016).

Operational definition: it is a set of procedures consistent with the total quality management aims to enhance institutions' performance in both: public and private sectors.

\section{Previous Literature}

Alic \& Ideskog (2016) conducted a study in Sweden aimed to investigate Hoshin Kanri nethodology in order to provide a general framework and suggesting some management practices based on this methodology. The sample of the study consisted of (14) Japanese companies operating in Sweden. To achieve the study purposes, personal interview was used. The results revealed that the structuring of Hoshin Kanri methodology in the companies can take a sequential form based on a set of clear steps or a set of cyclic steps. The results also showed that clarifying the basic elements of Hoshin Kanri methodology motivates companies to use it as an effective way to enhance the level of quality culture.

(Senol \& Dagli 2017), in Turkey, aimed to identify the quality of services provided to secondary school students from principals and teachers perceptions. The sample of the study consisted of (10) principals and (22) secondary school teachers. To achieve the study purposes, a personal interview was used. The findings of the study indicated the need to provide training courses for secondary school principals and teachers in order to enhance their understanding of quality culture. The finding also revealed that principals' perception about quality culture was related to finding effective teaching methods, the relationship between students and principal and the relationship between the instructing and counseling services provided by teachers.

Souad, Messaouda \& Maazouzi ( 2017) conducted a study in Algeria aimed to develop a model based on Hoshin Kanri methodology and its application to companies. A literature review, critical study was used. The content of (11) previous studies addressing the use of Hoshin Kanri methodology was analyzed. The results revealed that Hoshin Kanri methodology provides an effective tool in clarifying the strategic vision of an institution, as it works to establish an integration between a set of organizational objectives within a comprehensive organizational model based on a set of effective administrative processes. The results showed that Hoshin Kanri methodology is also an effective method for strategic planning, which positively affects the administrative processes. Furthermorem it provides a holistic methodology for integrating the strategic objectines into routine administrative practices, and for applying the concept (plan, implement, check and evaluate) to enhance the performance of administrative operations.

(Dziminska, Fijallkowska \& Sulzowski, 2018) aimed to develop a model for higher education institutions based on quality culture. To achieve the objectives of the study, a qualitative design based on content analysis was used, through reviewing a number of previous literature and studies addressed quality culture. The results of the study showed that the proposed model contributes to enhancing concepts related to organizational culture, such as loyalty, trust, and organizational reputation. In addition to that, the results indicated that may contribute to the decision-making process, and that the proposed model demonstrates the need for higher education institutions to enjoy a level of transparency and clarity, as well as the need for reliable administrative systems based on the development of their quality culture.

\section{Study Methodology}

The proposed educational role for Jordanian secondary was built on the basis of Hoshin Kanri methodology for developing quality culture. A qualitative design based on content analysis was used, as it is considered a type of qualitative analysis through which documents, reports, scientific research, images, sounds and videos are examined, and a method used by social workers to reveal different patterns according to their frequency. Furthermore, it is an objective design because the analysis is related to the subject as it is and is not related to personal analyzes (Hsieh \& Shannon, 2005). The two researchers refer to the theoretical literature represented in the scientific studies related to quality culture and Hoshin Kanri methodology. 


\section{Results}

To answer the study question, an appropriate educational role has been suggested for Jordanian secondary schools to develop their quality culture of based on the concepts and foundations of Hoshin Kanri methodology for developing quality culture, in light of what was presented in the previous literature and the results reached in the current study.

First: Defining the proposed educational role of Jordanian secondary schools based on Hoshin Kanri methodology to develop their quality culture.

Based on Hoshin Kanri methodology for developing a culture, the proposed educational role for Jordanian secondary schools can be defined as the activities and practices through which the strategic plans, sought by Jordanian secondary schools, is achieved by its principals, teachers and activities, via selecting the priorities and practices for all employees; the proper use of laws and regulations; providing the tools required for their development and applying structured audits to ensure a sustained improvement.

\section{Second: The proposed educational role philosophy}

Based on the concepts and foundations of Hoshin Kanri model, the philosophy of the proposed educational role includes enabling secondary school administration to develop and deploy quality culture within school's departments and structure, with the aim of achieving high levels of quality culture among principals, teachers and students.

\section{Third: The proposed educational role objectives}

Based on the concepts and foundations of Hoshin Kanri model, the proposed educational role for secondary schools aims to identify the plans, procedures, mechanisms and tools that contribute to developing their quality culture, as follows:

1. The work to enhance the performance of secondary schools personnel in line with quality culture development within school's environment, ensuring the suitability of secondary school strategies with concepts and foundations related to quality culture development in various aspects and establishing a school climate to deploy and develop quality culture among principals, teachers and students.

2. Amending the curricula, as well as classroom and extra-curricular activities to include the concepts of quality culture, and ensuring that the necessary requirements and materials are available to enhance their development.

3. Ensuring the establishment of quality culture and its concepts among principals and teachers, so that efforts are directed towards developing the quality culture of the educational services provided to students, and among students themselves.

4. Benefiting from the experiences, plans and programs of secondary schools with a high classification of quality culture in their management and systems, with the aim of developing the ongoing plans and programs in line with the development of quality culture in the secondary schools of Jordan.

5. Activating the role of technology through introducing students to aspects related to quality culture, and introducing them to the behaviors, concepts, and foundations associated with it in order to attract their attention and enhance their awareness about it.

6. Enhancing the level of awareness, and providing the necessary training courses that focus on quality culture through the partnerships between secondary schools and local community institutions.

\section{Fourth: The basic principles of the proposed educational role}

The proposed educational role based on Hoshin Kanri methodology is built upon a set of basic principles, namely:

1. Ensuring that a secondary school's objectives are relevant to the changes of its external environment, as well as focusing on determining the necessary procedures and steps to deal with those changes.

2. The focus on addressing the gaps between quality culture's deploying strategies faced by the administration of a secondary schools.

3. The participation in the process of addressing these gaps through enhancing collaboration between the parties of the high school whether they are administrative or executive parties.

4. Emphasizing that the set objectives meet the needs of students of secondary schools.

5. The focus on activating top-down and down-top planning in the process of setting objectives and following up and evaluating their attainment. 
6. Determining the criteria used to measure high school's performance in meeting the strategic objectives.

7. Linking the long-term strategic plans sought by secondary schools with the short-term interim objectives, and making the necessary adjustments to the plans developed, relying on the feedback obtained by the school administration to make sure the means used are consistent with the objectives set by the secondary schools.

8. The focus on achieving the competitive advantage of secondary schools by developing the quality culture within secondary schools, selecting principals and teachers with competence to develop the quality culture of secondary schools and providing them with appropriate training.

9. Expanding the activities that reinforce the quality culture in secondary schools through conducting classroom and extra-curricular activities, and ensuring that quality culture is included in all academic levels.

\section{Fifth: The of the proposed educational role's areas of interest:}

The areas, in which the proposed educational program for secondary schools is interested in, are as follows:

1. Knowledge area: A secondary school must be prepared to embed the quality culture based on Hoshin Kanri methodology; to have knowledge and information about developing the quality culture and its impact on various aspects of school administration and educational processes; to ensure that the quality culture is included in the curricula, activities, programs and practices in order to ensure that principals and teachers are keeping up with new developments commensurate with what is required by the quality culture, as this requires the school administration's endeavor to identify what is necessary to adequately maintain the quality culture's sustainability; and to be familiar with the methods used to assess quality culture's development level in secondary schools.

2. Skills and experiences area: Activating Hoshin Kanri model contributes to achieving positive results by making use of principal's and teachers' experiences about quality culture, in addition to the focus on increasing their expertise about culture quality and the foundations associated with Hoshen Kanri model, whereas the availability of opportunities to develop the of principal's and teachers' skills and experiences about quality culture concepts and foundations contributes to its application at work and its activation among students.

3. working strategies area: It includes: ensuring that the appropriate annual plan is prepared; defining the long and short term objectives that the high school seeks to achieve, ensuring its understanding and directing the efforts of all levels and departments towards achieving it; operations redeployment strategies in the departments; evaluating the performance periodically; taking advantage of the feedback in order to develop the performance; activating the strategies that reinforce teamwork and cooperation in order to ensure the deployment of quality culture at all institutional levels; using the Code of Professional Conduct to ensure the commitment of principal, teachers and school personnel to qualityrelated actions and practices, with a view to ensuring transparency, credibility, accountability, and responsibility. The aforementioned are considered important aspects contribute to making changes in the institution's organizational structure and at various administrative levels.

4. The institutional performance area: Hoshin Kanri methodology focuses on daily institutional performance. It requires the presence of monitoring, follow up and evaluation systems on an ongoing basis, taking the necessary measures to address the exposed problems during work, and the use of criteria and indicators to measure a secondary school performance with a view to guide the educational and administrative decisions in the right direction.

5. Creative ideas area: Activating Hoshin Kanri model includes: making use of creative ideas and leaving the conventional ideas in school's management and activities, and the process of providing school and educational services to students; making sure to afford what is necessary for providing suitable environment helps to implement those ideas within the school; and making sure that these ideas are applicable. This is done through the creative ideas contributed to finding solutions for the faced problems, such as: problems related to performance and practices in school, problems related to curricula and problems related to teaching methods.

6. School environment area: The environment of the school must be prepared and verified as safe to be inclusive for quality culture concepts, due to its great impact on its activation. The readiness of the school administration and its desire to activate the quality culture are among the main and motivating factors for its application in all aspects related to the school, such as: appointing teachers and monitoring their 
performance and evaluation, the safety of decision-making processes related to the mechanisms of developing a culture of quality, and constantly restructuring the educational environment.

7. Curriculum area: The high level of quality in the curricula is one of the main factors to achieve quality for secondary schools. Therefore, it is imperative to ensure that the curriculum provided by the school includes what contributes to providing students with the necessary knowledge, life and academic skills, and the promotion of values, principles and ethics. These curricula also need to be distinguished by containing the study materials and taking into account the academic differences among students, to include practical activities for the scientific curricula; to ensure that they are applied within the school environment. Furthermore. it is also important to work on activating the E-Learning, take advantage of blended learning in the curriculum development process, enabling students to benefit more from them, and enabling them to evaluate students after the school shift.

8. Educational services area: The educational services are about providing the necessary services that ensure the raising of educational competence level for students and for all the parties benefiting from the educational process, so as to ensure the establishment of the plans and strategies that works to improve and develop the educational process, as well as ensuring that teachers have sufficient knowledge in their field of specialization, and that they are familiar with the curriculum. The success of the educational services depends on the effective planning of educational services provided to students, so that the study plans are coordinated and built in line with what the students learn before. The educational services also represent the basis on which the advanced educational plans are built, as they are planned through constructing them to be carried out in a specific time frame; which, therefore, contribute to providing education for all students without distinguishing between them.

\section{Sixth: The proposed educational role elements}

The proposed educational role includes a range of elements that contribute to developing the quality culture in secondary schools, based on the concepts and foundations related to Hoshin Kanri methodology. These elements can be listed as follows:

1. The analysis before setting a plan: This stage identifies the necessary requirements to enhance the institutional performance, and the extent to which the administrative and organizational processes of quality systems are include. It also works to ensure that a school administration seeks to provide educational services that meet the educational needs of all students categories in secondary schools.

2. Task Development: Successful development of quality culture requires school administration to ensure that the various processes in the school are controlled and followed up, as well as ensuring the clarity of e objectives sought by the administration throughout quality development and the use of Hoshin Kanri methodology in the administrative process. In addition to that, it requires school administration to ensure the availability of the needed tools and facilities for its development; to train and prepare teachers and administrators; and to provide effective communication channels within school's internal environment, as well as with the external parties associated with the school.

3. Developing the added value: This includes ensuring the development of secondary school's actual performance; and ensuring its ability to achieve growth in students' academic performance and other skills related to the educational process. The added value also activates the accountability, responsibility and assessment, in addition to establishing the foundations related to school personnel's behavior.

4. Developing the vision: The vision of the secondary school is embodied in the objectives it seeks to achieve, through which the school's massage, objectives, policies, future directions and quality level emerge. Whereas, it should be ensured that the school is on its way towards applying its vision within the concepts and foundations of quality culture; developing the parties involved in the educational process; the effectiveness of contacting and communication processes among different levels and administrative departments; and the ability to build effective relationships with the local community.

5. Setting short-term and long-term objectives: Hoshin Kanri methodology includes defining the management of the secondary school for the objectives, and ensuring that they are clear to all individuals working in the school. It includes the objectives sought by the school, whether they are short and long term ones. Therefore, these objectives would be clear in its vision and massage. It also includes ensuring that the short-term objectives are identified and can be fulfilled within a specific time frame, as well as the use school's available resources.

6. Developing annual plans: This includes defining the required outcomes from school performance; the policies and strategies used to obtain these outcomes; evaluating and assessing the schools' students 
and personnel; and identifying the performance's indicators and measurement methods used to develop performance and the time frame for completing tasks as well.

7. Deploying quality culture: The areas related to quality culture are to be focused here, through employing the role of the parties involved in the secondary school (principals, teachers and students) in order to develop and enhance its level; developing appropriate plans to ensure the development of quality culture; and ensuring the use of appropriate strategies affecting performance and able to make a change. Teachers are considered one of the most influencing factors on the educational process, as the quality level in the educational process and educational reform is closely related to them, and is affected by the qualifications level and the experience they possess. Their competency level is related to obtaining an adequate and appropriate training to enhance the quality level of the educational process .

8. Setting standards: The secondary school administration determines expected indicators it seeks to achieve in relation to the objectives in the short and long term. It also tries to make sure that the efforts are directed towards achieving them, and that the requirements of the determined standards are met through the use of the available resources and personnel's daily performance. These standards should be realistic and logical. In the event of a gap between the actual and expected performance, an activation of external relations (between the secondary school and quality systems' specialists, experts and educators) are required.

9. Setting objectives: Setting goals is an element indicates what a secondary school seeks to achieve by developing quality culture. There are a set of sub-objectives stems from the main objectives sought by the secondary school, which require the harmony and integrity between the activities and performance to be fulfilled. It is also imperative to ensure that school personnel participate in setting the objectives according to their competence. It includes the strategic planning to ensure the quality of operations and aspects related to education; defining the requirements for developing quality culture in institutional performance by arranging the objectives based on their priorities and importance; teachers' determining of the necessary adjustments for the curricula, teaching methods, classroom and extracurricular activities, the school environment, and other aspects related to students' educational services, being the target group of the educational process.

10. Feedback: The feedback helps identify the results of the performance of the secondary school, its personnel and school environment, the indicators and measures of performance used, the work's established mechanisms, and the extent to which these mechanisms add value to students' performance and the development of quality culture within the secondary school. In addition to that, feedback is the means by which strengths are identified and strengthened, and by which weaknesses' causes are identified to be overcome. feedback is also a means of continuous improvement, especially in light of periodic follow-up and performance evaluation.

11. Challenges and difficulties: There are a number of challenges and difficulties that may face secondary schools, as they can be referred to as follows:

- Human and material resources: Challenges related to human resources include secondary schools' poor experience with quality systems; the lack of appointing and polarizing qualified and experienced personnel; the absence of continuous training for personnel to ensure the clarity of the concepts and principles related to quality systems; the absence of the mechanisms and means motivate them to be committed to implementing quality systems within the work environment; the absence of individual performance standards to determine the level of school personnel, assessing their performance and ensuring that they meet the level required from them at work; and their failure to show the practices and behaviors that constitute quality systems. Challenges relate to material resources include the lack of adequate devices and equipment to keep up sufficiently with the teaching and learning technologies; the absence of continuous updating and maintenance for schools' facilities, as it must be suitable for all school's personnel and students, especially those with special needs. Therefore, its important to ensure the availability of different and sufficient learning resources for educational programs, and provide communication and information management tools in order to ensure that the horizontal and vertical communication process is activated from top to bottom and vice versa.

- School environment: The weakness of the relationships within the school's internal environment causes the absence of many pillars related to quality culture, such as teamwork, cooperation and the activation of social, cultural and democratic principles and values. Therefore, this would limit the cohesion of the individuals working within the school and causes proof of negative behavior and practices, such as increasing the levels of intolerance, ostracism, and discrimination, which cause a gap 
between the administration and its personnel; increasing their pursuit to achieve personal interests at the expense of the interests sought by secondary schools in general; and increasing the difficulty of following-up and evaluating and deploying quality within school environment.

- The school's relationship with the local community: The absence of effective relationships between school and society are negatively affecting its relationship with parents and institutions that can provide them with financial support, as well as affecting the experiences related to quality systems and their reputation as well. Thus, the absence of such relations is considered among the most dangerous factors that affect the school's long-term sustainability and its ability to develop in the future.

\section{Seventh: Obstacles related to implementing the proposed educational role}

The proposed educational role may face several obstacles, including:

1. Principals and personnel low level of qualification to apply the concepts and foundations of quality and Hoshin Kanri methodology, in addition to the use of traditional methods in the administrative and educational process.

2. The low level of technology available in secondary schools, which limits the ability to develop the systems of evaluation, follow-up and monitoring performance, in addition to that it limits the ability to transfer curricula from traditional to electronic.

3. The limited activation of performance indicators to evaluate the quality culture, its standards and indicators to performance measurement related to it among principals and teachers, which causes a weakness upon identifying the indicators' concepts and objectives, in addition to a weakness in the interpretation of the implications of those indicators.

4. The need for time and efforts to apply and implement quality culture in secondary schools based on Hoshen Kanri's concepts and foundations.

5. The limited training programs, related to developing quality culture and introducing Hoshin Kanri model, that the Ministry of Education provides to teachers and principals.

6. The weak channels of communication between the principals and school personnel, and the limited use of technology for achieving communication and information transfer effectively.

7. The limited financial resources available to secondary schools, which, therefore, limit the activation of quality in all its aspects, as well as limiting their application in the programs and activities that increase the development of quality culture in school.

8. School personnel's resistance to change, as they prefer traditional methods of administration and education due to seeing that change would cause them to have an additional workload.

9. Do not continuo to apply Hoshin Kanri methodology to develop quality in the long-term, whereas its work depends on the commitment level of all parties related to the institution.

10. The low readiness of secondary schools to develop quality culture in light of the large increase in the number of students and population, and the crises caused by asylum to Jordan that led to cultural diversity.

11. The poor coordination between universities and higher education institutions to prepare and train teachers on how to deal with quality systems and their foundations, as well as dealing with the lack of practical application.

Eighth: Mechanisms for overcoming the obstacles

To overcome these obstacles, we must do the following:

1. Providing the necessary training courses that contribute to enhance continuously personnel's professional development in terms of quality culture and Hoshin Kanri methodology, as well as training them on how to implement them in work and school environment.

2. Allocating the necessary financial resources needed to provide the equipment and tools for technology and quality development at all levels of the school, as well as making efforts to include technology in the educational process.

3. Developing suitable indicators to evaluate the performance of secondary school personnel at individuals, departments and administration levels. In addition to find appropriate strategies to enhance the level of personnel and their knowledge related to the application of quality in the various activities and tasks assigned to them.

4. Benefiting from the experiences of educational institutions that are characterized by their high levels of quality culture; applying Hoshin Kanri methodology for developing quality culture; and raising 
awareness about the importance of applying it through the use of experts and specialists in quality systems. Therefore, this would accelerate their activation and acceptance within secondary schools' working systems.

5. Providing training programs related to developing quality culture by the Ministry of Education for teachers and principals, as well as benefiting from other countries' experiences in developing curricula, teaching methods, and mechanisms for activating quality culture in various educational sectors, including secondary schools.

6. Striving towards finding all the required means to activate communication channels between the principals, teachers and secondary school personnel at the horizontal and vertical levels, in addition to ensuring the participation of school's teachers and personnel in strategic decision-making processes and the mechanisms related to evaluation and follow-up. Furthermore; ensuring teachers' participation in developing teaching methods and curricula; and benefiting from personnel's experiences and creative solutions that may contribute to developing quality culture in secondary schools.

7. Awarding financial and moral awards and incentives for secondary schools' personnel in order to motivate them towards applying quality culture and being familiar with new changes achieved as a result of activating quality culture on the basis of Hoshin Kanri methodology, as well as encouraging the principals and teachers to conduct researches on quality culture and Hoshin Kanri methodology in order to expand their knowledge about it and suggest mechanisms for developing it in the schools they work in.

8. Allocating adequate and sufficient financial support to activate quality systems by the Ministry of Education, as well as developing plans within a specific determined time frame and using clear evaluation criteria.

9. Establishing binding laws to implement Hoshin Kanri methodology used for developing quality culture in secondary schools in the short and long term; raising awareness about the importance of activating it; and periodically evaluating a secondary school performance in applying the methodology, and assessing the extent to which it develops the quality culture.

10. Establishing effective relationships and partnerships with institutions at the local and international levels in order to find appropriate places for teaching refugee students, ensuring the appropriateness of the curricula offered to them, and allocating an appropriate and safe environment for them.

11. The focus of higher education institutions on preparing school personnel and students by providing study materials including quality and related concepts and foundations; applying a number of methodology related to quality culture, including Hoshin Kanri methodology; and higher education institutions' need to develop study materials in accordance with national and international standards.

\section{Discussion}

Based on Hoshin Kanri model, an appropriate educational role for secondary schools has been proposed to achieve quality culture in light of what was proposed by previous studies, the results of the current study and the theoretical literature related to it. The study revealed that the appropriate educational role includes the activities, practices, tasks, plans, strategies, policies and systems on which secondary, represented by its principals, teachers and personnel, are based. Therefore, quality is employed in the various fields and aspects related to the secondary school.

Sattler \& Sonntag (2019) stressed that quality has become a key requirement in various educational institutions, as it cannot be easily avoided or not followed due to its impact and necessity in achieving the objectives of those institutions. Therefore, the promulgation of laws and legislations related to developing quality culture within a school environment is considered the cornerstone of setting quality into application in various aspects and areas related to schools; ensuring the integrity of administrative structures; and establishing the foundations used to evaluate schools' performance and educational process outcomes. In addition to that, these laws and legislations are considered responsible for finding effective relationships and partnerships at the local and global levels in order to provide the requirements of its application in all areas and activities related to quality culture, and in the operations of school administration.

Bashiwa (2016) pointed out that the pursuit of developing systems and policies related to schools is characterized by its continuity, ensuring that it achieves the objectives of the educational process, and that it keep pace with the standards sought by educational institutions at the local and global levels. Consequently, the strive for ensuring the quality of the services provided to students, moving towards allocating the requirements needed for enhancing the quality of those services, and determining the extent to which it meets 
the students' needs from the educational process, is one of the fundamental aspects that school administrations should work hard to activate in order to develop their quality culture.

And at school administration level, it has been revealed that quality systems are highly dependent on the principal, being the leader and instructor of tasks, the activator of legislations in the school, and the issuer of decisions. The principal's role in activating quality systems requires his awareness of the various aspects associated with them, in addition to finding appropriate methods and strategies for implementing quality systems. It is also the responsibility of the principal to ensure that practices and behaviors issued by school's personnel are directed towards achieving the established objectives and plans.

Mahdid (2017) indicated that developing the quality culture affects the administrative and organizational aspects of institutions, and the processes of decision-making, in addition to being affected by the principal's competence and their ability to make decisions. Thus, preparing and training principals on how to follow the concepts and foundations of quality, and Hoshin Kanri methodology would greatly assist in applying it, and ensuring their implantation among their personnel.

The proposed educational role indicated that deploying quality culture is one of the tasks assigned to school administration, whereas the success of the principal to implement the strategies depends on his/her experience and ability to encourage school personnel to cope with quality systems and ensure their deployment in various processes and tasks, as well as encouraging them towards accepting them not being afraid of the changes that may arise.

Avila (2018) indicated that school administration is the factor affecting quality culture in schools by making a difference on all its personnel, the approved human and material resources and the level of social responsibility it addresses. Thus, the development of quality culture has an impact on all aspects and parties related to secondary schools.

Furthermore, the proposed educational role has focused on the importance of human resources efficiency in developing a quality culture, and enhancing participation of secondary schools' teachers and personnel in the process of developing its plans, objectives and strategies. This would, therefore, contribute to benefiting from their experiences in the field of education.

Goodewin \& Kosnik (2013) stressed that teacher's role is to control and organize activities related to students, to strive to provide them with appropriate experiences, and to develop their various skills. thus, the adherence to the concepts and foundations of quality culture, and benefiting from Hoshin Kanri methodology in the tasks assigned to the teacher contributes greatly to the development of quality culture, being the essence of the educational process, and the most interactive person with students. In addition to that, quality culture is achieved through the teacher's benefiting from his/her experience in the educational process; employing those experiences in developing the academic, social, thinking skills, and in developing areas related to quality culture within the classroom and school environment.

Madani (2019) stressed that providing an appropriate environment for students helps them gain knowledge and benefit from the educational services provided to them. Hence, the presence of competent and experienced personnel and teachers contributes significantly to the commitment to laws, and the promotion of ethical actions and practices.

With regard to the feedback, the proposed educational role has indicated its importance in a number of aspects, being a means to identify the strengths and weaknesses; a mechanism for evaluating performance; and a method used in determining the results of school performance. Furthermore, the implementation of quality systems based on Hoshin Kanri methodology depends on the presence of feedback, periodical reports (to determine the level of achievement and exposed problems), and solutions to address them, thus his requires an ongoing process of follow-up, evaluation and determination of performance results.

Hassan \& Fan (2016) asserts that the application of quality contributes to addressing a number of obstacles encountered in schools, such as the presence of parties resistant to change, and the absence of practical training on quality systems. Referring to the proposed educational role, it has focused on the need for parties to participate in the application of quality systems; the need to provide appropriate training for personnel; the need to encourage and motivate them to accept the changes; and the need to identify necessary requirements for developing quality culture in the secondary schools.

\section{Recommendations}

In light of the above results, the study recommends adopting the proposed educational role to confront the challenges and difficulties facing secondary schools in developing their quality culture, and holding training courses to educate secondary school personnel on developing it based on Hoshin Kanri methodology. 
Furthermore, it recommends the coordination and cooperation between the Ministry of Education and the local/international institutions to held and organize training courses that enhance the vocational performance of school's personnel, and then to be familiarize with mechanisms with the concepts and foundations related to quality systems.

\section{References}

Abdel-Daim, (2015). Anti-inflammatory and immunomodulatory effects of Spirulina platensis in comparison to Dunaliella salina in acetic acid- induced rat experimental colitis European Scientific Journal, 12(15),

Alice \& Ideskog. (2016). Hoshin Kanri - the Japanese way of piloting: An exploratory study of a Japanese strategic management system. 4th Digitala Vetenskaplige Arkivet.

Barton, L. \& Ambrosini, V. (2013). The moderating effect of organizational change cynicism on middle manager strategy commitment. The International Journal of Human Resource Management, 24(4), 721-746.

Bennet, T. (2017). Creating a culture: how school leaders can optimize behavior. UK: Department of Education. AVILA, (2018). Out of the crisis. Cambridge: MIT Center for Advanced Engineering Study.

Dziminska, M., Fijallkowska, J. \& Sulzowski, L. (2018). Trust-based quality culture conceptual model for higher education institutions. Sustainability, 10, 1-22.

Gouili. (2017). Impact of academic leadership on faculty's motivation, and organizational effectiveness in higher education system ResarchGate

, 7(2), 119-126.

Goodewin, A. \& Kosnik, C. (2013). Quality teacher educators quality teachers? Conceptualizing essential domains of knowledge for those who teach teachers. Teacher Development, 17(3), 334-346.

Hassan, A. \& Fan, I. (2016). Obstacles hindering TQM implementation in secondary schools in Saudi Arabia. Retrieved 15/1/2020 From: https://www.researchgate.net/publication/311307834_OBSTACLES_H INDERING_TQM.

Hutchins, D. (2008). Hoshin Kanri: The strategic approach to continuous improvement. Aldershot: Gower Publishing, Ltd.

Madani, R. (2019). Analysis of educational quality, a goal of education for policy. Higher Education Studies, 9(1), 100-109.

Makovec, D. (2018). The teacher's role and professional development. International Journal of Cognitive Research in Science, Engineering \& Education, 6(2), 33-45.

Martensson, K. \& Roxa, T. (2015). Academic development in a world of informal learning about teaching and student learning. International Journal for Academic Development, 20(2), 109-112.

Melander, A., Lofving, M., Andersson, D., Elgh, F. \& Thulin, M. (2016).

Introduction to Hoshin Kanri strategic management system in manufacturing SMEs. Management Decision, $54(10), 2507-2523$.

Nicholas, J. (2014). Hoshin kanri and critical success factors in quality management and lean production. Total Quality Management and Business Excellence, 27(3), 1-15.

Sattler, C. \& Sonntag, K. (2019). Quality cultures in Higher education institutions- development of the quality culture inventory. Germany: Springer.

Senol, H. \& Dagli, G. (2017). Increasing service quality in education: views of principals and teachers. EURASIA Journal of Mathematics Science and Technology Education, 13(8), 4857-4871.

Sharon, W. (2017). Tentatively exploring the learning potentiatities of postgraduate distance learners, interaction with other people in their life context: Distance. Education, 34(1), 175-188.

Souad, D., Messaouda, C. \& Maazouzi, K. (2017). Planning using Hoshin Kanri. International Journal of Academic Research in Economics and Management Sciences, 6(4), 1-13.

Witcher, B. (2014), Hoshin Kanri through the eyes of English language texts. Perspectives on Performance, 11(1), 16-24.

Zairi, M. \& Alan, E. (2014). Excellence is born out of effective strategic deployment: the impact of Hoshin planning. International Journal of Applied Strategic Management, 2(2), 1-28. 